\title{
Similar prevalence of enteroviral genome within the myocardium from patients with idiopathic dilated cardiomyopathy and controls by the polymerase chain reaction
}

Department of Cardiological Sciences, St George's Hospital Medical School, London P J Keeling

A L P Caforio

W J McKenna

Department of Clinical Genetics, St George's Hospital Medical School, London

$S$ Jeffery

$\mathbf{R}$ Taylor

Department of Immunology, The

London Hospital,

London

G F Bottazzo

Department of Histopathology, St George's Hospital Medical School, London

M J Davies

Correspondence to: Dr P J Keeling, Department of Cardiological Sciences, $\mathrm{St}$ George's Hospital Medical School, Cranmer Terrace, London SW 17 ORE.

Accepted for publication 22 June 1992

Philip J Keeling, Stephen Jeffery, Alida L P Caforio, Rohan Taylor, Gian F Bottazzo, Michael J Davies, William J McKenna

\begin{abstract}
Objective-To assess the prevalence and significance of enteroviral genome within myocardial biopsy specimens taken from patients with idiopathic dilated cardiomyopathy and from controls.
\end{abstract}

Design-Prospective evaluation of myocardial tissue for the presence of an enteroviral genome by the polymerase chain reaction.

Setting-A tertiary referral centre for patients with idiopathic dilated cardiomyopathy.

Patients-Tissue for the study came from 50 consecutive patients with dilated cardiomyopathy, 41 with other forms of heart disease and 34 from coroners' necropsy cases.

Results-Enteroviral genome was detected in $6 / 50(12 \%)$ patients with dilated cardiomyopathy and $13 / 75(17 \%)$ of the controls (not significant). No differences were seen between dilated cardiomyopathy patients with or without myocardial enteroviral genome in respect of age; duration of symptoms; proportion of patients with a premorbid acute viral illness, excess alcohol consumption, or hypertension; New York Heart Association functional class; measures of left ventricular function; or endomyocardial histology. Within the control group enteroviral genome was detected in $3 / 15(20 \%)$ patients with ischaemic heart disease, $2 / 19(10.5 \%)$ with valvar heart disease, $1 / 5(20 \%)$ with specific heart muscle disease, $0 / 2(0 \%)$ with congenital heart disease, and $7 / 34(20.6 \%)$ cases of sudden death. During 2-52 month follow up (mean 22) $15 / 44$ (34\%) patients without myocardial enteroviral genome and $2 / 6$ (33\%) with myocardial enteroviral genome died suddenly or required orthotopic heart transplantation for progressive heart failure.

Conclusions-These findings do not support the hypothesis that persistent enteroviral infection is of pathogenic or prognostic importance in dilated cardiomyopathy but they are consistent with enterovirus being a common environmental pathogen.

(Br Heart J 1992;68:554-9)

Enteroviruses, particularly coxsackie B viruses, are thought to be important in the pathogenesis of myocarditis and idiopathic dilated cardiomyopathy. ${ }^{12}$ Although there is considerable support for an aetiological role of coxsackie virus in murine myocarditis and dilated cardiomyopathy ${ }^{34}$ direct evidence in man is lacking. ${ }^{5-7}$ The principal supporting evidence linking enteroviral infection to dilated cardiomyopathy is derived from several retrospective serological studies. ${ }^{29}$ Enteroviruses, however, are endemic pathogens and enteroviral serology is highly complex; despite the introduction of specific assays for enteroviral immunoglobulin $\mathbf{M}^{10}$ the significance of positive enteroviral serology remains unclear. ${ }^{11}$ Recombinant deoxyribonucleic acid technology has been used to detect viral genome within myocardial biopsy material from patients with dilated cardiomyopathy and myocarditis. Initial studies of slot blot hybridisation $^{1213}$ suggested that enteroviral genome was present in more than $50 \%$ of patients with established cardiomyopathy. Other groups, with different hybridisation techniques, have failed to confirm such a high prevalence of enteroviral genomic material in biopsy specimens from patients with myocarditis or dilated cardiomyopathy, ${ }^{14-16}$ and accumulated data suggest a prevalence of $10 \%-$ $20 \%$. The discrepancies in the results of these studies may reflect differences in clinical diagnosis and the variable sensitivity and specificity of hybridisation assays used.

Gene amplification by the polymerase chain reaction (PCR) is a rapid and extremely sensitive technique. ${ }^{1718}$ Jin et al, using an enteroviral specific polymerase chain reaction in combination with slot blot hybridisation, reported a low prevalence $(10 \%)$ of enteroviral genome within the myocardium of patients with dilated cardiomyopathy and myocarditis. ${ }^{16}$ Unfortunately the low number of controls in this study makes interpretation of these results extremely difficult. In our study, we report the application of an enterovirus specific 
PCR gene amplification technique to myocardial biopsy specimens taken from 50 patients with clinical dilated cardiomyopathy and from 75 biopsy specimens taken from patients with other forms of cardiac disease or cases of sudden death in the community.

\section{Patients and methods PATIENTS \\ Dilated cardiomyopathy}

A clinical diagnosis of dilated cardiomyopathy was made according to World Health Organisation (WHO) criteria ${ }^{19}$ in 50 patients ( 38 men, 12 women) whose ages ranged from 17-60 (mean (SD), $40(12)$ ) years. Fifteen patients had a history of chronic excess alcohol consumption (men $>8$ units a day and women $>6$ units a day for the preceeding five years) and nine patients had a historyof hypertension and were included in the study. All patients had an enlarged left ventricle on echocardiography (mean left ventricular end diastolic size $68(8) \mathrm{mm}$ ) when expressed as a percentage of the calculated normal size by the method of Henry et al (mean $143 \%(19) \%$ (normal range $<112 \%$ )). ${ }^{20}$ All patients had impaired left ventricular systolic function as assessed by echocardiography (fractional shortening $13 \%(7) \%$ ), angiography (ejection fraction $28 \%(8) \%$ and radionuclear ventriculography (ejection fration $23 \%(8) \%$. Functional classification with the new York Heart Association (NYHA) classification showed 24 patients were in class I, seven in class II, 16 in class III, and three in class IV. Right ventricular endomyooardial biopsies were taken transvenously in all patients and samples were taken at the time of cardiac transplantation from the explanted heart of six patients. Biopsies were sectioned, stained with haematoxylin and eosin, and assessed by light microscopy with the Dallas criteria. ${ }^{21}$ Due to the absence of diagnostic features on histology in dilated cardiomyopathy those biopsies in which there was fibrosis in the absence of an inflammatory cell infiltration were termed established dilated cardiomyopathy.

\section{Controls}

Seventy five myocardial control tissues were taken, mostly at the time of cardiac surgery, from patients with valvar disease $(n=19)$, coronary artery disease $(n=15)$, congenital heart disease $(n=2)$, or specific heart muscle disorders (hypertrophic cardiomyopathy ( $\mathrm{n}=$ 3 ), cardiac amyloidosis $(n=1)$, right ventricular dysplasia $(n=1)$. Additional cardiac control tissue $(n=34)$ was taken at the time of coroners' necropsy from people who died suddenly. Although 12 of these deaths were due to myocardial infarction, 24 cases had no cardiac pathology and died from non-cardiac causes (violent deaths $(n=6)$; cerebrovascular accident $(n=5)$; carcinoma $(n=4)$; pulmonary embolism $(n=3)$; unknown $(n=6)$. Most samples were taken from the right ventricular septum.
ENTEROVIRAL SPECIFIC GENE AMPLIFICATION BY THE POLYMERASE CHAIN REACTION

The polymerase chain reaction is a recent development in molecular hybridisation technology, which enables a minute quantity of specific nucleic acid to be detected within a clinical sample after its extensive and selective amplification. In this assay total cellular ribonucleic acid was extracted from biopsy specimens and used to synthesise the more stable complementary deoxyribonucleic acid that is used in the subsequent polymerase chain reaction. With specially designed and enteroviral specific oligonucleotide primers, a region of the enteroviral complementary deoxyribonucleic acid was selectively amplified by the polymerase chain reaction. The amplified fragment of deoxyribonucleic acid then underwent gel electrophoresis and was transferred to a membrane that was hybridised with a radiolabelled enterovirus specific deoxyribonucleic acid probe and was then filmed by autoradiography.

Preparation of ribonucleic acid from myocardial samples

Endomyocardial samples were immediately snap frozen and stored in liquid nitrogen until required. Intact ribonucleic acid was extracted with RNAagents (Promega) from myocardial biopsy specimens by the one step procedure of Chomczynski and Sacchi. ${ }^{22}$ Briefly, specimens were denatured and homogenised in guanidine thiocyanate with citrate/sarcosine/ $\beta$ mercaptoethanol buffer. Ribonucleic acid "was extracted with phenol and chloroform and precipitated twice with isopropanol. The ribonucleic acid was then washed in $75 \%$ ethanol, vacuum dryed, and stored under $100 \%$ ethanol at $-70^{\circ} \mathrm{C}$ until required. Before use these samples were centrifuged at $4^{\circ} \mathrm{C}$ and then resuspended in $10 \mu$ l of RNAase free water. The quality of the ribonucleic acid was checked by northern blotting with a radiolabelled probe to actin and by absorbance spectrophotometry $\left(A_{260: 280}\right)$.

Preparation of coxsackievirus positive control ribonucleic acid

Coxsackievirus ribonucleic acid was prepared as a positive control from a stock of Coxsackie $B 3$ virus $\left(10^{6}\right.$ infectious agents $\left./ \mu \mathrm{l}\right)$ harvested in phosphate buffered saline (PBS) from infected Vero cells when $50 \%$ of the cells exhibited cytopathic effects. Cells wee suspended in guanidine solution and ribonucleic acid was extracted as above.

\section{Oligonucleotides}

Enteroviruses show a high degree of nucleotide sequence homology and the oligonucleotides used in this assay have previously been shown to be highly specific for enteroviral genome and capable of detecting a broad range of enteroviruses. $^{2324}$ The structures of this primer pair (E1 and E2) and the hybridisation probe E3 have been published previously and gene amplification has been shown to be enterovirus specific and produce a 196 base-pair fragment. $^{23}$ 
Viral complementary deoxyribonucleic acid synthesis and the polymerase chain reaction First strand complementary deoxyribonucleic acid synthesis and subsequent polymerase chain reaction gene amplification was performed with the Perkin-Elmer Cetus Gene-Amp Kit. First strand complementary deoxyribonucleic acid synthesis was achieved in a total volume of $20 \mu \mathrm{l}$ by random hexamers using $2 \mu \mathrm{l}$ of sample material and $50 \mathrm{U}$ moloney murine leukemia virus reverse transcriptase. The final concentration of magnesium used was 3.75 $\mathrm{mM}$. These mixtures were left at room temperature for 10 minutes, then incubated at $42^{\circ} \mathrm{C}$ for 15 minutes, $99^{\circ} \mathrm{C}$ for five minutes, and finally for five minutes at $5^{\circ} \mathrm{C}$. The polymerase chain reactions were performed in a total volume of $100 \mu \mathrm{l}$ using $1 \mathrm{U}$ AmpliTaq (PerkinElmer Cetus) and $1 \mu \mathrm{l}$ each of a primer pair (E1 and $\mathrm{E} 2$, concentration $80 \mathrm{mg} / \mathrm{ml}$ ) with a final magnesium concentration of $2.35 \mathrm{mM}$. The mixtures were incubated at $95^{\circ} \mathrm{C}$ for two minutes and then step cycled in a two temperature cycle with one minute at $95^{\circ} \mathrm{C}$ and one minute $60^{\circ} \mathrm{C}$ for 55 cycles and finally incubated for seven minutes at $60^{\circ} \mathrm{C}$ (Techne PHC-1). Amplified products were stored at $-20^{\circ} \mathrm{C}$ until required. In each assay coxsackie virus positive
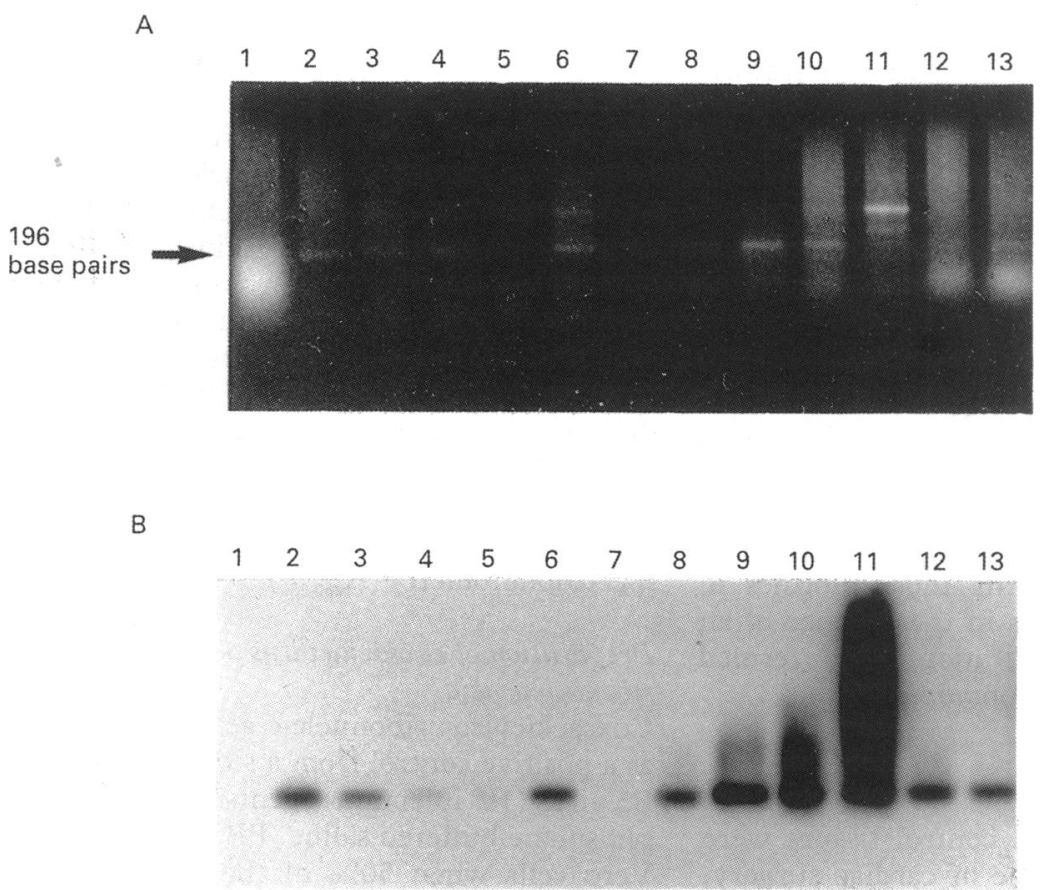

Figure (A) Agarose gel after electrophoresis of amplified product of polymerase chain reaction produced from myocardial samples from patients with dilated cardiomyopathy and controls. Clear bands are seen at 196 base pairs in most of the lanes of the gel except the negative control lanes. However in some lanes it is difficult to know whether a viral band is present or not (lane 1-a smear of nucleic acid obscures the region, lanes 11 and 12 -faint bands may be present). Additional higher molecular weight bands produced from non-specific gene amplification can be seen in lanes 6 and 11. (B) corresponding autoradiographs after Southern blotting and hybridisation with radiolabelled E3 shows that the bands seen on the gel at 196 basepairs hybridise with E3, and are thus specific for enterovirus. The greater sensitivity of the assay after Southern blotting and hybridisation with radiolabelled E3 is confirmed by a hybridisation signal being produced in the apparent absence of $a$ band on the gel (lanes 8,11 and 12). Non-specific amplification products do not hybridise with $E 3$ and are thus non-enteroviral. Nonspecific hybridisation between E3 and cellular nucleic acid is shown as a smear of radioactivity in lane 11 and highlights one of the major limitations of slot blot hybridisation. Lane 1, negative control (Vero cell RNA); lanes 2-6, patients with dilated cardiomyopathy; lane 7, negative control (no RNA); lane 8, patient with valvar heart disease; lanes 9-11, victims of community sudden death; lanes 12, 13 patients with ischaemic heart disease. samples and two negative samples, one with ribonucleic acid extracted from a normal myocardium and one containing no ribonucleic acid, were used as controls.

\section{Gel electrophoresis and Southern blotting}

A total of $15 \mu \mathrm{l}$ of amplification product underwent electrophoresis at $100 \mathrm{~V}$ into $1.5 \%$ agarose gels in TBE $(110 \mathrm{~g}$ Tris, $55 \mathrm{~g}$ boric acid/ 1, $20 \mathrm{ml} 1 \mathrm{M}$ EDTA). Gels were stained with ethidium bromide to detect deoxyribonucleic acid by illumination with ultraviolet light. The deoxyribonucleic acid was transferred to Hybond- $\mathrm{N}+$ membranes (Amersham) with $0.4 \mathrm{M}$ sodium hydroxide as the alkali transfer buffer. One hundred ng of E3 was end labelled with $\gamma^{32} \mathrm{P}[\mathrm{ATP}]$ by $\mathrm{T} 4$ polynucleotide kinase. Membranes were prehybridised for 30 minutes and hybridised for two hours at $37^{\circ} \mathrm{C}$, in $10 \mathrm{ml}$ $20 \times$ SSPE ( $3 M$ sodium chloride, $0.18 M$ sodium hydrogen phosphate, $0.018 M$ EDTA), $2 \mathrm{ml} 100 \times$ Denharts' solution (Ficoll 1\%, polyvinylpyrrolidone $1 \%$, bovine serum albumin $1 \%$ ) and $2 \mathrm{ml} 10 \%$ sodium dodecyl sulphate (SDS) made up to $40 \mathrm{ml}$ in distilled water. The membranes were washed in $2 \times$ SSC with $0 \cdot 1 \%$ SDS at $50^{\circ} \mathrm{C}$ and then exposed overnight to an $x$ ray film at $-70^{\circ} \mathrm{C}$ with intensifying screens. To assess the sensitivity of the assay 10-fold serial dilutions of virus were prepared and $10^{1}$ to $10^{9}$ virons added to biopsy material from enterovirus negative myocardium. The ribonucleic acid from these specimens was then extracted with subsequent complementary deoxyribonucleic acid synthesis, polymerase chain reaction gene amplification, gel electrophoresis, and Southern blotting.

\section{STATISTICAL ANALYSIS}

Statistical analyses were performed with the Fisher's exact test with Yate's correction. Values are expressed as mean (SD) with $\mathrm{p}<$ 0.05 being considered significant.

\section{Results}

THE POLYMERASE CHAIN REACTION ASSAY

First strand complementary deoxyribonucleic acid synthesis with random hexamers produced more intense bands than did the use of the specific downstream primer (E1). The polymerase chain reaction had highly specific gene amplification with stringent annealing conditions, no extension cycle, and low enzme concentrations. This allowed completion of the large number of step cycles without undue non-specific gene amplification. Some assays with control tissue did produce non-specific gene amplification products. Further analysis of these samples showed that three to four times as much ribonucleic acid had been extracted and used in the assay and this non-specific gene amplification could be reduced with smaller amounts of ribonucleic acid in the assay. Gel electrophoresis of amplified product alone produced clear bands at 196 base pairs in 15 assays. Subsequent Southern blotting confirmed that these bands hybridised with radiolabelled E3. In some assays a significant degree of non-specific hybridisation with genomic ribonucleic acid and complemtary deoxyribo- 
Table 1 Clinical features and results of enteroviral polymerase chain reaction in patients with dilated cardiomyopathy (mean $(S D)$ )

\begin{tabular}{|c|c|c|}
\hline & \multicolumn{2}{|c|}{ Enteroviral genome } \\
\hline & Positive & Negative \\
\hline $\begin{array}{l}\text { Number }(\mathrm{n}=50) \\
\text { Age }(\mathrm{yr}) \\
\text { Duration of symptoms (months) } \\
\text { NYHA class }(\mathrm{n})\end{array}$ & $\begin{array}{l}6 \\
45 \quad(16) \\
59 \quad(58) \\
I(3), \text { III }(3)\end{array}$ & $\begin{array}{l}44 \\
40 \quad(12) \\
35 \quad(49) \\
\text { I }(21), \text { II }(7), \text { III (13), } \\
\text { IV }(-3)\end{array}$ \\
\hline $\begin{array}{l}\text { Acute viral illness }<6 \text { months } \\
\text { LVEDD (mm) } \\
\text { LVEDD \% } \\
\text { FS (\%) } \\
\text { Histology }\end{array}$ & $\begin{array}{cl}1 & (17 \%) \\
69 & (10) \\
147 & (17) \\
13 & (9) \\
\text { Established } 6\end{array}$ & $\begin{array}{l}11(25 \%) \\
68(9) \\
143(20) \\
13(7) \\
\text { Established 21, normal 15, } \\
\text { myocarditis 2, healing } \\
\text { myocarditis 2 }\end{array}$ \\
\hline
\end{tabular}

*According to Dallas criteria.

LVEDD, left ventricular end diastolic dimension; LVEDD\%, percentage of calculated left ventricular end diastolic dimension (normal range $<112 \%)^{20} ; \mathrm{FS}$, fractional shortening.

nucleic was found, but this could easily be distinguished from the specific band that hybridised at 196 base-pairs. Furthermore, after Southern blotting a positive hybridisation signal was obtained in four more assays in which no band had been seen initially after gel electrophoresis. The figure shows an agarose gel on which polymerase chain reaction amplified product from patients with dilated cardiomyopathy and control tissues has undergone electrophoresis (fig A), and the corresponding autoradiograph is also shown for direct comparison (fig B). To find the sensitivity of the assay serial dilutions of stock virus were added to biopsy samples and analysed as above. This showed that the assay was capable of detecting less than $10^{2}$ infectious virions in each biopsy specimen.

\section{PATIENTS WITH DILATED CARDIOMYOPATHY}

Enteroviral genome was detected in $6 / 50(12 \%)$ patients with dilated cardiomyopathy. Table 1 gives the clinical and biopsy features of these patients together with the results of the polymerase chain reaction assay. No differences in dilated cardiomyopathy paients with or without myocardial enteroviral genome were noticed in age, duration of symptoms, proportion of patients with a premorbid acute viral illness, excess alcohol consumption, hypertension, NYHA functional class, measures of left ventricular function, or results of endomyocardial histology. During follow up of the six patients with myocardial enteroviral genome, three patients remained unchanged at 7-25

Table 2 Evidence from hybridisation studies of enteroviral involvement in human dilated cardiomyopathy and myocarditis

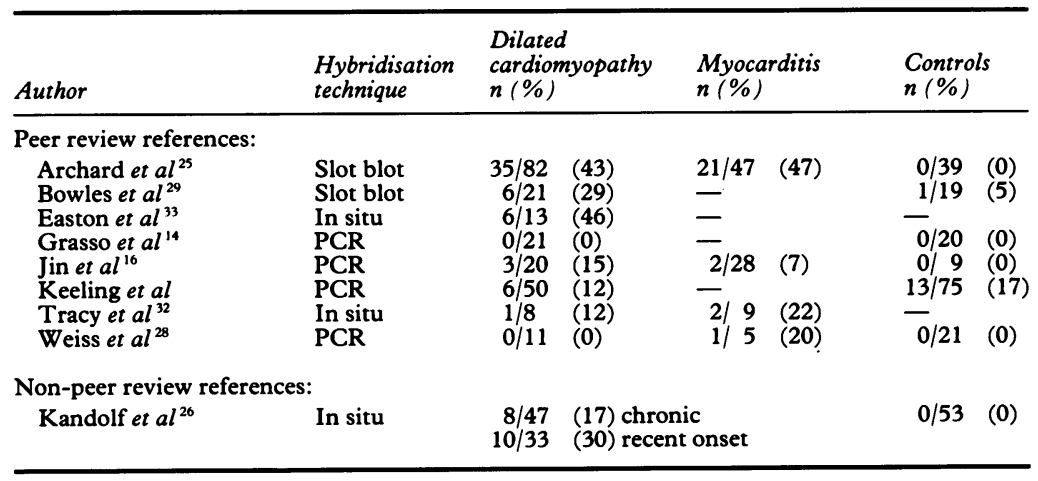

(mean 18.7) months, one patient was improved at 27 months, one patient received an orthotopic heart transplantation at three months and one patient died suddenly at seven months. During the 2-52 (mean 22) month follow up of 44 patients without myocardial enteroviral genome, six died suddenly and nine received an orthotopic heart transplantation for progressive heart failure. Of the remaining patients 16 remained clinically stable ( 11 NYHA class $I$, five NYHA class II), nine had improved (NYHA class I) and two had deteriorated (one NYHA class II, one NYHA class III). No differences were noticed in the clinical outcome between those patients with and without enteroviral genome within the myocardium.

\section{CONTROL PATIENTS}

Enterovirus-specific gene amplification by polymerase chain reaction was noted in $13 / 75$ $(17 \cdot 3 \%)$ of the control population. This was not significantly different when compared with the results of the dilated cardiomyopathy patients. Subgroup analysis showed the presence of myocardial enteroviral genome in $2 / 19(10.5 \%)$ with valvar heart disease, $3 / 15$ $(20 \%)$ with ischaemic heart disease, $1 / 5(20 \%)$ with specific heart muscle diseases, $0 / 2(0 \%)$ with congenital heart disease, and $7 / 34(20.6 \%)$ community sudden deaths including $3 / 12$ $(25 \%)$ cases who died from myocardial infarction.

\section{Discussion}

In this study we applied a highly sensitive and specific polymerase chain reaction technique to detect enteroviral genome in myocardial tissue taken from 50 patients with dilated cardiomyopathy and from 75 controls (41 with other forms of heart disease and 34 from coroners' necropsy cases). Enteroviral genome was detected within the myocardium in $6 / 50(12 \%)$ patients with dilated cardiomyopathy but was not associated with any feature of clinical, histological, or functional assessment. Furthermore, the presence of enteroviral genome within the myocardium of these patients did not confer on them an adverse prognosis as has been proposed. ${ }^{25}$ Our study also showed that enteroviral genome was present in myocardial tissues in a similar proportion of controls $(17 \%)$.

All the patients studied with dilated cardiomyopathy have been extensively characterised with strict diagnostic criteria and are being regularly followed up. The control tissues were taken either at the time of cardiac catheterisation or surgery or from coroners' necropsies. The quality of the extracted ribonucleic acid, a particular concern for the necropsy tissues because of its possible degradation after death, was found to be adequate in all groups of patients. The polymerase chain reaction used in this study was highly sensitive and capable of detecting as few as 100 copies of enteroviral genome within a single endomyocardial biopsy specimen. The hybridisation probe (E3) used has previously been shown to be pan-enteroviral and capable of detecting a wide range of enteroviruses. ${ }^{23}$ 
Some non-specific hybridisation with genomic ribonucleic acid or complementary deoxyribonucleic acid was noted but this was easily distinguished from enteroviral specific hybridisation after gel electrophoresis and southern blotting of the amplification product.

We found enteroviral genome within the myocardium of $12 \%$ of patients with dilated cardiomyopathy: similar proportions were reported by other workers who used in situ hybridisation ${ }^{1526}$ or polymerase chain reaction techniques ${ }^{162728}$ but less than those reported by Archard et al ${ }^{25}{ }^{29}$ who used the technique of slot blot hybridisation (table 2). A limitation of slot blot hybridisation is non-specific hybridisation with genomic ribonucleic or deoxyribonucleic acid. This has been recently highlighted by Jin et al ${ }^{16}$ who found that before gene amplification under conditions of low stringency, the extracted ribonucleic acid showed considerable nonspecific hybridisation with a high number of false positive results. A further problem in several of the reported studies are the differences in selection of patients with dilated cardiomyopathy, and in particular to the presence of previous systemic hypertension or excess alcohol consumption. The finding of enteroviral genome within the myocardium of $17 \%$ of control tissues has not been reported. Previous studies, however, with sensitive and specific hybridisation techniques, have been limited in the number of control tissues analysed. ${ }^{1624}$ The only report that has assayed a significant number of control samples with in situ hybridisation has failed to detect enteroviral genome within the myocardium. ${ }^{26}$ Whether this reflects the lower number of copies of enteroviral genome within the control tissues compared with those from patients with dilated cardiomyopathy due to the lower sensitivity of in situ hybridisation remains to be established.

Historically the principal supporting evidence linking enteroviral infection to dilated cardiomyopathy is derived from retrospective serological studies. ${ }^{29}$ Infection with enteroviruses is common and infection with a single serotype often induces a multitypic response against several different serotypes with most people developing neutralising antibodies to a large range of serotypes early in adult life. Also there is usually considerable uncertainty in finding the time of the start of disease indilated cardiomyopathy as the preclinical phase of the disease is often very long. The introduction of specific assays for enteroviral immunoglobulin $M$ promised to help with the identification of recent or persistent infection. ${ }^{10}$ High levels of enterovirus specific immunoglobulin $M$ have, however, also been reported in a number of other conditions including chronic relapsing pericarditis ${ }^{10}$ and postviral fatigue syndrome ${ }^{11}$ as well as in a matched control population taken from the community. Whether there is a difference in the prevalence or persistence of this enterovirus specific immunoglobulin $M$ response between patients with dilated cardiomyopathy and a matched control population is not known at present. It is pertinent to remember that type I insulin dependent diabetes mellitus and amyotrophic lateral sclerosis were initially linked to enteroviral aetiologies on the basis of raised enteroviral serology, but subsequent studies with appropriate controls have failed to support this claim. ${ }^{3031}$ Also, a clear association between the presence of enteroviral specific immunoglobulin $M$ and the presence of enteroviral genome within the myocardium has not been confirmed in patients with dilated cardiomyopathy. ${ }^{32}$

The significance of enteroviral genome within the myocardium in the small proportion of patients with dilated cardiomyopathy and its relation to active viral replication is unclear. Perhaps only active viral replication or infection with a particular type of enterovirus is responsible for the development of dilated cardiomyopathy, and this may only occur in patients with dilated cardiomyopathy and not the controls. Markers of active viral replication (for example enteroviral capsid protein, VP1) and the application of type specific enteroviral probes have not been assessed in dilated cardiomyopathy. Also the absence of a clear relation between the presence of viral genome and of histopathological damage within the myocardium has not been shown in humans by in situ hybridisation. ${ }^{33}$ It is of course still possible that enteroviral infection may be important in pathogenesis of disease by acting as a trigger for the induction of autoimmunity as has been reported in the chronic form of murine myocarditis. ${ }^{34-36}$ In this circumstance it would perhaps not be surprising with highly sensitive hybridisation techniques to find enteroviral genomic sequences in the absence of whole competent infectious viruses within the myocardium. The low prevalence of enteroviral genome, however, within the myocardium of patients with dilated cardiomyopathy and in a similar proportion of controls does not provide support for a pathogenic role of persistent enteroviral infection in dilated cardiomyopathy.

PJK is a British Heart Foundation research fellow and ALPC is supported by a research fellowship from the European Society of Cardiology. We also acknowledge the helpful comments of D Steve Tracy with regard to the ribonucleic acid amplification.

1 Burch GE, De London: JA Pasquale NP. Viral myocarditis. Cardiomyopathies. Churchill, 1964:99-115.

2 Cambridge G, MacArthur CG, Waterson AP, Goodwin JF Oakley CM. Antibodies to Coxsackie B viruses in congestive cardiomyopathy. Br Heart $J$ 1979;41:692-6.

3 Wilson FM, Mirander QR, Chason JL, et al. Residual pathologic changes following murine coxsackie virus $A$ and B myocarditis. Am J Pathol 1969;55:253-65.

4 Woodruff JF. Viral myocarditis: a review. Am J Patho 1980;101:425-84

5 Sutton G, Harding H, Truehart R, Clark H. Coxsackie B4 myocarditis in an adult: successful isolationof virus from ventricular myocardium. Aerospace Medicine 1967;38: 66-9.

6 Matoba Y, Matsumori A, Ohtani H, et al. A case of biopsyproven myocarditis pregressing to autopsy-proven dilated cardiomyopathy. Clin Cardiol 1990;13:732-7.

7 Quigley PJ, Richardson PJ, Meany DT, et al. Long term follow-up in biopsy proven myocarditis: progression to dilated cardiomyopathy. Circulation 1986;74(suppl II): 142.

8 Kawai C. Idiopathic cardiomyopathy: A study on the infection-immune heory as a cause of the disease. Jpn Circ $J$ 1971;35:765-70.

9 Fletcher GF, Colemen MT, Ferino PM, Marine WM Wenger NK. Viral antibodics in patients with primary 
myocardial disease. Am J Cardiol 1968;21:6-10

10 Muir P, Nicholson F, Tilzey AJ, Signy M, English TA, Banatvala JE. Chronic relapsing pericarditis and dilated cardiomyopathy: serological evidence of persistent Entovirus infection. Lancet 1989;1:804-7.

11 Miller NA, Carmichael HA, Calder BD, et al. Antibody to Coxsackie $B$ virus in diagnosing postviral fatigue syndrome. BMJ 1991;302:140-3.

12 Bowles NE, Richardson PJ, Olsen EG, Archard LC. Detection of Coxsackie-B-virus-specific RNA sequences in
myocardial biopsy samples from patients with myocarditis and dilated cardiomyopathy. Lancet 1986;1:140-3.

13 Archard L, Bowles N, Olsen E, Richardson P. Detection of persistent coxsackie $B$ virus RNA in dilated cardiomyopathy and myocarditis. Eur Heart $J$ 1987;8(supp J):437-40.

14 Grasso M, Arbustini E, Silini E, et al. Search for coxsackievirus B3 RNA in idiopathic dilated cardiomyopathy using gene amplification by polymerase chain reaction. using gene amplification by

15 Tracy S, Wiegand V, McManus B, et al. Molecular approaches to enteroviral diagnosis in idiopathic cardiomyopathy and myocarditis. J Am Coll Cardiol 1990;15:1688-94.

16 Jin O, Sole MJ, Butany JW, et al. Detection of Enterovirus RNA in myocardial biopsies from patients with myocaditis and cardiomyopathy using gene amplification by polymerase chain reaction. Circulation 1990;82:8-16.

17 Ross RS, Chien KR. Of molecules and myocardium. PCR diagnosis of viral myocarditis in cardiac biopsies. Circulation 1989;82:294-5.

18 Rotbart HA. Enzymatic RNA amplification of the enteroviruses. J Clin Microbiol 1990;28:438-42.

19 Bradenberg RO, Chazov E, Cherian G, et al. Report of the WHO/ISFC task force on definition and classification of the cardiomyopathies. Circulation 1981;64:1397-9.

20 Henry WL, Gardin JM, Ware JH. Echocardiographic measurements in normal subjects from infancy to old age. measurements in normal subjects
Circulation 1980;62:1054-61.

21 Aretz HT, Billingham ME, Edwards WD, Factor FM, Fallon JT, Fenolio JJ, et al. Myocarditis, a histopathologic definition and classification. Am J Cardiovasc Pathol 1987;1:3-14

22 Chomczynski P, Saachi N. Single-Step method of RNA isolation by guanidinium thiocyanate-phenol-chloroform extraction. Anal Biocem 1987;162:156-9.

23 Chapman NM, Tracy S, Gauntt CJ, Fortmueller U. Molecular detection and identification of Enterovirus using enzymatic amplification and nucleic acid hybridisation. J Clin Microbiol 1990;28:843-50.

24 Tracy C. Comparison of Genomic homologies in the coxsackie group by use of cDNA:RNA Dot-Blot hybridisa- tion J Clin Microbiol 1985;21:371-4.

25 Archard LC, Bowles NE, Cunningham L, et al. Molecular probes for detection of persisting enterovirus infection of human heart and their prognostic value. Eur Heart $J$ 1991;12(supp D):56-9.

26 Kandolf $R$, Canu A, Klingel K, et al. Molecular studies on enteroviral heart disease. In: Brinton MA, Heinz FK, eds. New aspects of positive strand RNA viruses. Washington DC: American Society of Microbiology, 1990:340-8.

27 Tracy S, Chapman NM, Pistillo JM. Detection of human enteroviruses using the polymerase chain reaction. In: Berke Y, Donai G, eds. Frontiers in Virology (Vol 1)Diagnosis of human viruses by PCR technology. Berlin: Springer-Verlag, 1991:331-44.

28 Weiss LM, Movahed LA, Billingham ME, Cleary ML. Detection of Coxsackievirus B3 RNA in myocardial tissues by the polymerase chain reaction. Am J Pathol tissues by the polym
$1991 ; 138: 497-503$

29 Bowles NE, Rose ML, Taylor P, et al. End-stage dilated cardiomyopathy. Persistence of enterovirus RNA in
myocardium at cardiac transplantation and lack of immune response. Circulation 1989;80:1128-36.

30 Kohne D, Gibbs C, Smiths R, Meinke W, Tracy S, White L. Virus detection by nucleic acid hybridisation: examination of normal and amyotrophic lateral sclerosis tissues for the presence of poliovirus. J Gen Virol 1981;65:223-30.

31 Foulis AK, Farquharson MA, Cameron SO, McGill M, Schonke H, Kandolf R. A search for the presence of the enteroviral capside protein VP1 in pancreases of patients with type 1 (insulin-dependent) diabetes and pancreases and hearts of infants who died of coxsackieviral myocarditis. Diabetologia 1990;33:290-8.

32 Tracy S, Chapman NM, McManus BM, Pallansch MA, Beck MA, Carstens J. A molecular and serologic evaluation of enteroviral involvement in human myocarditis. tion of enteroviral involvement in
$J$ Mol Cell Cardiol 1990;22:403-14.

33 Easton AJ, Eglin RP. The detection of coxsackievirus RNA in cardiac tissue by in situ hybridization. J Gen Virol 1988;69:285-91.

34 Neu N, Rose NR, Alvarez F, Beisel KW. Coxsackievirus induced myocarditis in mice: cardiac myosin autoantibodies do not cross-react with the virus. Clin Exp Immunol 1987;69:566-74.

35 Neuman DA, Lane JR, LaFond WA, et al. Elution of autoantibodies from the hearts of coxsackievirus-infected mice. Eur Heart J 1991;12(supp D):113-6.

36 Rose NR, Neu N, Neuman A, Herskowitz A. Myocarditis: a postinfectious autoimmune disease. In: Schultheiss HP, ed. New concepts of viral heart disease. Berlin: SpringerVerlag, $1988 ; 139-47$ 